\title{
Formation and Persistence of Brine on Mars: Experimental Simulations throughout the Diurnal Cycle at the Phoenix Landing Site
}

\author{
E. Fischer, G.M. Martínez, and N.O. Rennó
}

\begin{abstract}
In the last few years, water ice and salts capable of melting this ice and producing liquid saline water (brine) have been detected on Mars. Moreover, indirect evidence for brine has been found in multiple areas of the planet. Here, we simulate full diurnal cycles of temperature and atmospheric water vapor content at the Phoenix landing site for the first time and show experimentally that, in spite of the low Mars-like chamber temperature, brine forms minutes after the ground temperature exceeds the eutectic temperature of salts in contact with water ice. Moreover, we show that the brine stays liquid for most of the diurnal cycle when enough water ice is available to compensate for evaporation. This is predicted to occur seasonally in areas of the polar region where the temperature exceeds the eutectic value and frost or snow is deposited on saline soils, or where water ice and salts coexist in the shallow subsurface. This is important because the existence of liquid water is a key requirement for habitability. Key Words: Mars-IcePerchlorates-Brine-Water-Raman spectroscopy. Astrobiology 16, 937-948.
\end{abstract}

\section{Introduction}

T HE DISCOVERY OF water ice and perchlorates at the surface and in the shallow subsurface of Mars is interesting because they could produce liquid saline water (brine) under Mars' present-day environmental conditions. Water ice was discovered in the shallow subsurface of polar and midlatitude regions (Boynton et al., 2002; Feldman et al., 2002; Mitrofanov et al., 2002; Byrne et al., 2009; Smith et al., 2009). Salts capable of melting this ice at Mars' present-day environmental conditions and producing brine were discovered in the polar and equatorial regions (Hecht et al., 2009; Glavin et al., 2013; Ming et al., 2014), suggesting that they are distributed globally. Evidence for salt hydrates and brine has been found in regions ranging from polar to equatorial latitudes (Rennó et al., 2009; Cull et al., 2010a; McEwen et al., 2011; Martín-Torres et al., 2015; Ojha et al., 2015), in spite of the martian air (Lewis et al., 1999) and top regolith (Meslin et al., 2013) being extremely dry and bulk deliquescence (brine formation by absorption of water vapor only) at Mars' low temperatures being too slow to explain the observed phenomena (Fischer et al., 2014).

We studied experimentally the formation and the persistence of brine throughout the diurnal cycle at the Phoenix landing site using Raman scattering spectroscopy and imag- ing. A previous study suggests that brine formation from water ice is the most likely mechanism to produce liquid water within the diurnal cycle (Fischer et al., 2014). We focus on the formation of brine by the contact of either surface or subsurface water ice with $\mathrm{Ca}\left(\mathrm{ClO}_{4}\right)_{2}$ because this salt is likely present at the Phoenix landing site (Hecht et al., 2009; Kounaves et al., 2014) and at Gale Crater (Glavin et al., 2013), suggesting that it is ubiquitous on Mars (Kounaves et al., 2014). Furthermore, the eutectic temperature of $\mathrm{Ca}\left(\mathrm{ClO}_{4}\right)_{2}$ is extremely low $\left(T_{\mathrm{E}} \sim\right.$ $199 \mathrm{~K}$ ) (Marion et al., 2010), and it changes phases at similar environmental conditions as a salt mixture closely matching the individual cation/anion concentrations found in the regolith of the Phoenix landing site on Mars' polar region (Nuding et al., 2015). Finally, we focus on $\mathrm{Ca}\left(\mathrm{ClO}_{4}\right)_{2}$ because liquid solutions of other perchlorate salts have already been studied in detail (Chevrier et al., 2009). It is likely that perchlorates have been deposited at the Phoenix landing site by atmospheric processes and concentrated into patches at the surface and in the shallow subsurface by freeze-thaw cycles (Rennó et al., 2009; Cull et al., 2014). Our study focuses on the simplest process, the interaction of salts with water ice. This is the first step for the full understanding of brine formation on Mars. In the future, we plan to study the formation of brine by the interaction of saline soils with water ice.

Department of Climate and Space Sciences and Engineering, University of Michigan, Ann Arbor, Michigan.

(C) E. Fischer et al., 2016; Published by Mary Ann Liebert, Inc. This Open Access article is distributed under the terms of the Creative Commons Attribution Noncommercial License (http://creativecommons.org/licenses/by-nc/4.0/) which permits any noncommercial use, distribution, and reproduction in any medium, provided the original author(s) and the source are credited. 


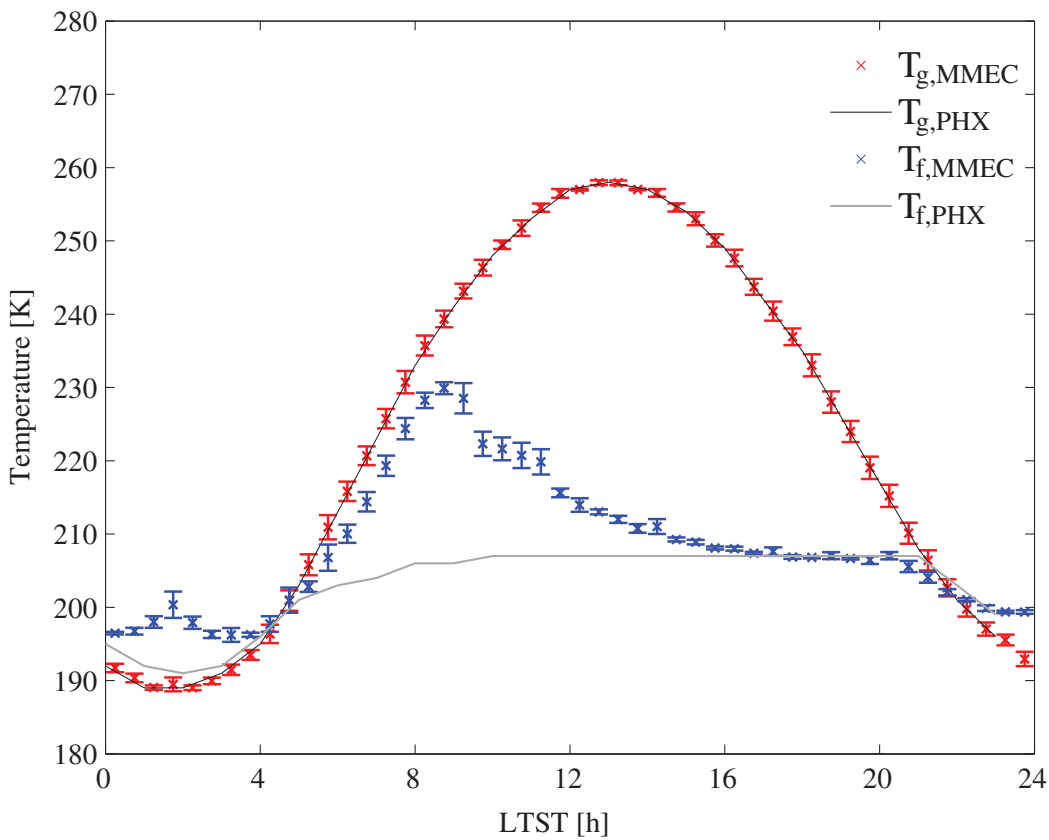

FIG. 1. Environmental conditions on Sol 19, when "soft ice" was unveiled by the Phoenix robotic arm in the Dodo-Goldilocks trench. The black and gray lines represent values from numerical simulations of the ground temperature and frost point of the surrounding air at the Phoenix landing site, while red and blue crosses represent the temperature and frost point measured inside the MMEC. The ground temperature first exceeds the $\mathrm{Ca}\left(\mathrm{ClO}_{4}\right)_{2}$ eutectic value $(199 \mathrm{~K})$ at $04: 32$, about $5 \mathrm{~min}$ before the first visual evidence for the formation of brine in the MMEC. Detailed calculations of the environmental conditions on this sol are provided in the Supplementary Material.
Results of four comprehensive laboratory experiments are discussed in this article. The first three experiments were designed to investigate the formation of bulk brine on the surface of Mars' polar region, such as in the material exposed in a shallow trench (Dodo-Goldilocks) excavated by the Phoenix robotic arm on Sols 18-19 of the mission (Smith et al., 2009). The fourth experiment investigates the evolution of $\mathrm{Ca}\left(\mathrm{ClO}_{4}\right)_{2}$ salt subjected to a lower-amplitude diurnal temperature cycle like that expected on the struts of the Phoenix lander where surface/shallow-subsurface material was splashed and formed spheroids (Rennó et al., 2009).

The Michigan Mars Environmental Chamber (MMEC) (Fischer et al., 2014) is used to simulate the environmental conditions throughout the full diurnal cycle of each experiment reported in this article. Sol 19 of the Phoenix mission is chosen as the baseline because ice was unveiled at a depth of $\sim 5 \mathrm{~cm}$ and removed with little effort around this sol (Smith et al., 2009), suggesting that it was likely frozen brine (Rennó et al., 2009; Cull et al., 2010a), which is much softer than freshwater ice.

\section{Experimental Setup}

All experiments reported in this study were conducted in the MMEC, a cylindrical chamber with internal diameter of $64 \mathrm{~cm}$ and length of $160 \mathrm{~cm}$. The MMEC is capable of simulating temperatures ranging from 145 to $500 \mathrm{~K}, \mathrm{CO}_{2}$ pressures ranging from 10 to $10^{5} \mathrm{~Pa}$, and the entire range of relative humidity at the Phoenix landing site (Fischer et al., 2014).

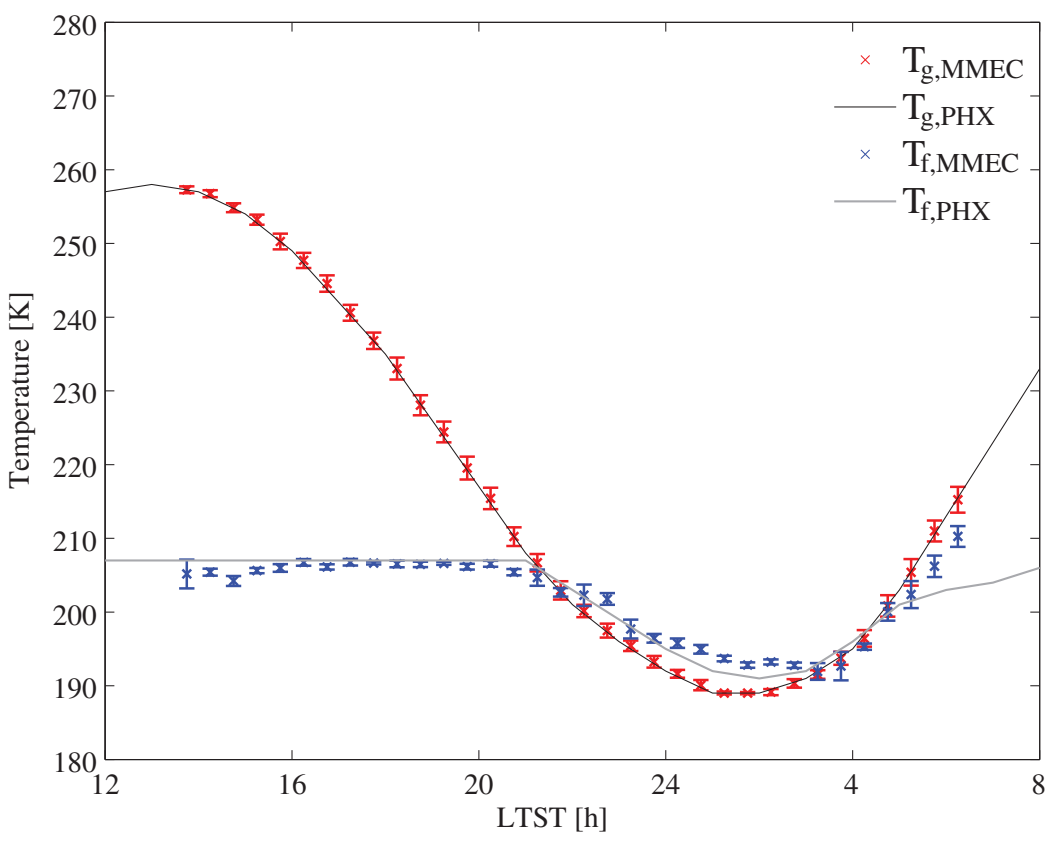

FIG. 2. As in Fig. 1, but for the second experiment. To ensure similar sample conditions as in the first experiment, the second experiment started with brine at the beginning of crust formation at 13:45. The experiment ended at $06: 30$ of the next sol, about $2 \mathrm{~h}$ after the sample temperature exceeded the eutectic value. 
FIG. 3. As in Fig. 1, but starting with a mix of water ice and calcium perchlorate at 04:00. Similar to the first experiment, the MMEC closely simulates the temperature in the trench (red crosses), but it overshoots the frost point temperature values inferred from the Phoenix measurements between 06:00 and 15:00 (blue crosses).

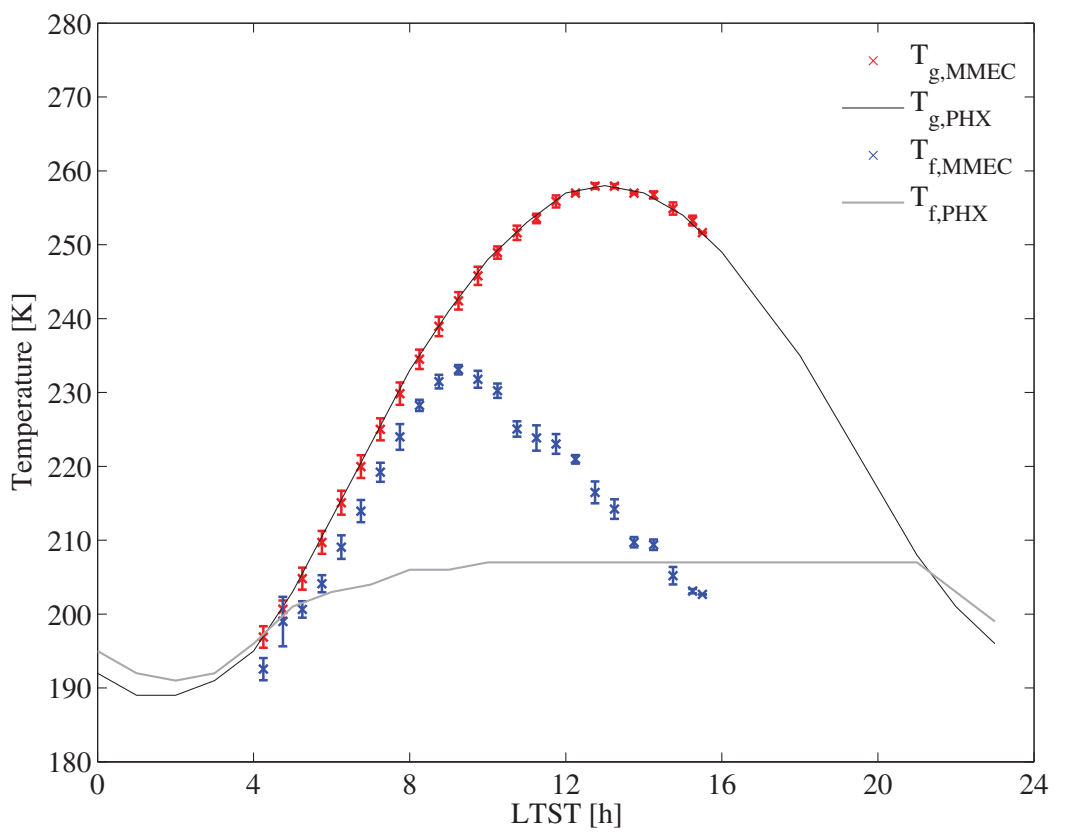

The first experiment was designed to study the formation of brine when salt is placed in contact with water ice, as it occurs when frost or snow are deposited on salty soil crusts. Distilled water was placed in a $0.3 \mathrm{~cm}^{3}$ cylindrical sample holder at laboratory ambient conditions, and the temperature of the sample holder was lowered to $\sim 190 \mathrm{~K}$, about $9 \mathrm{~K}$ below the eutectic temperature of $\mathrm{Ca}\left(\mathrm{ClO}_{4}\right)_{2}$, to freeze the sample. Then, a thin $(<2 \mathrm{~mm})$ layer of salt crystals with typical particle diameters $<300 \mu \mathrm{m}$ was placed on the top of the ice. Particles of this size can move easily, accumulate in low topographical features, and then be buried because they are the most easily transported by saltation (Kok and Rennó, 2009). In addition, layers of salt this thin were used because this thickness is within the penetration depth of the laser; thus the onset of the formation of brine anywhere in the sample can be detected. Our results are not sensitive to particle size because melting starts in the interface between salt crystals and ice, and Raman spectroscopy is capable of detecting its onset on the surfaces of the salt crystals. Next, the chamber pressure was reduced to $800 \mathrm{~Pa}$, the chamber's Earth air atmosphere was replaced by dry $\mathrm{CO}_{2}$, and then the sample temperature and the frost point temperature (of the MMEC's atmosphere) were continuously adjusted to follow those of the martian diurnal cycle starting at midnight.

The ground temperature and frost point temperature at the Phoenix landing site on Sol 19 (Fig. 1) were obtained by a combination of numerical modeling and measurements (see the Supplementary Material for details, available online at www.liebertonline.com/ast). The experimentally (MMEC) simulated ground temperature (red crosses) closely matches
FIG. 4. Sol 19 temperature at $0.5 \mathrm{~m}$ above the ground (the height of place on the Phoenix strut where spheroids were observed) at the Phoenix landing site. The black curve represents the diurnal evolution of the temperature $(0.5 \mathrm{~m}$ above the surface), while red crosses represent the temperature experimentally simulated in the MMEC. The frost point temperature was not simulated in this experiment. The diurnal temperature cycle at $0.5 \mathrm{~m}$ height has lower amplitude than at the ground, with higher minimum and lower maximum temperatures. This causes the brine to stay liquid for most of the diurnal cycle.

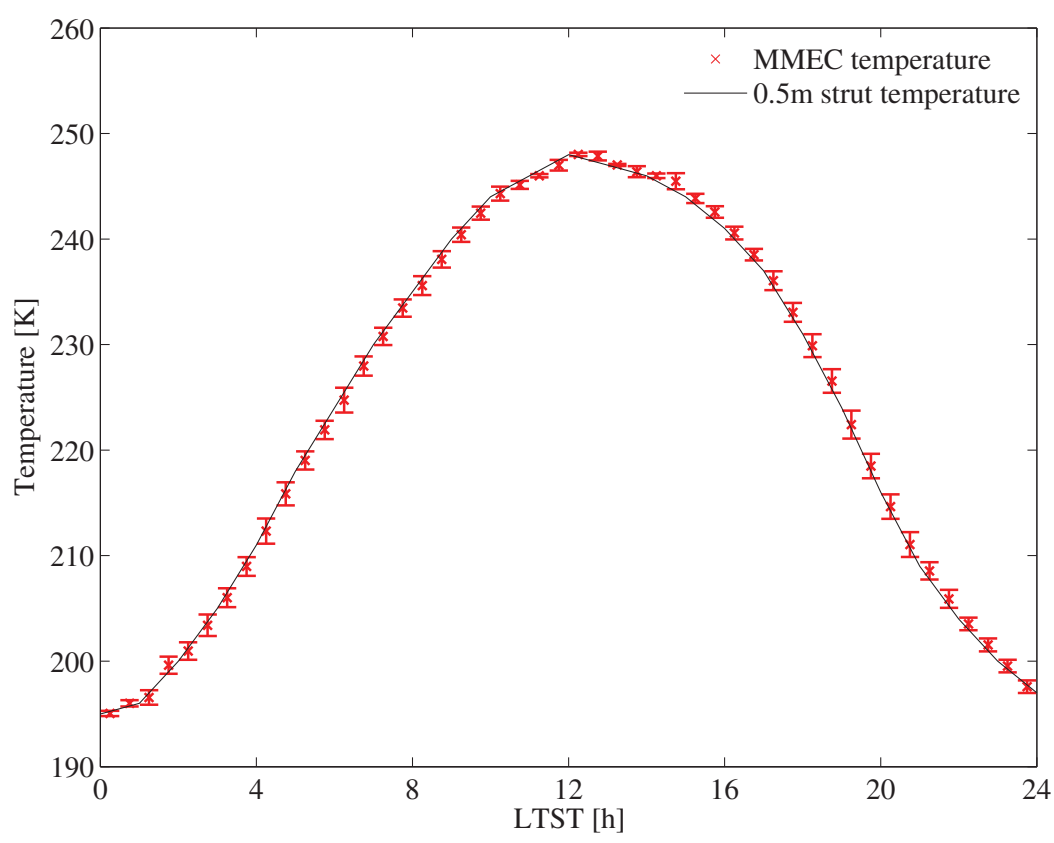




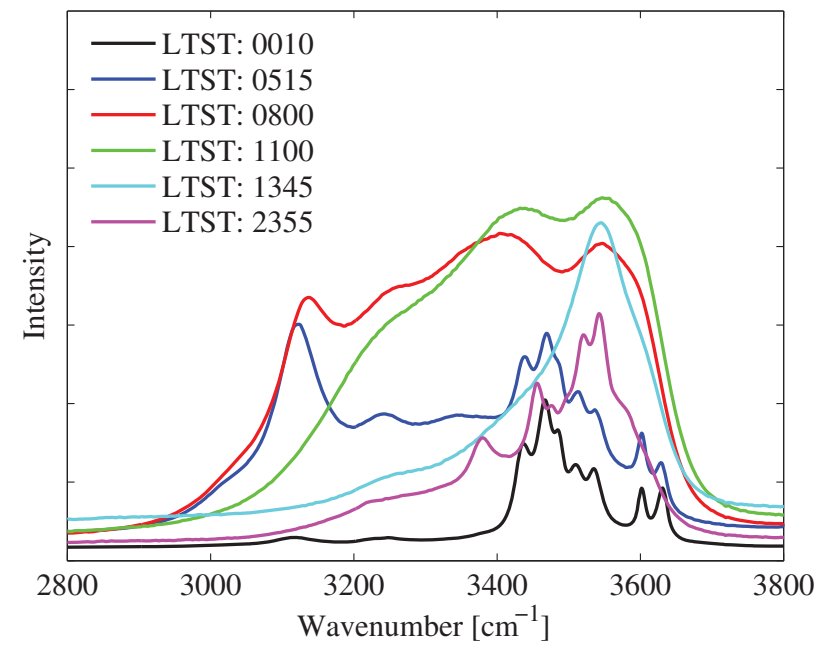

FIG. 5. Raman spectra in the $\mathrm{O}-\mathrm{H}$ stretching band throughout the full diurnal cycle shown in Fig. 1 (first experiment). The wavenumber and FWHM of the Gaussian components of each spectrum are shown in Table 1. The appearance of the broad peak at $3578 \mathrm{~cm}^{-1}$ in the spectrum taken at 08:00 clearly indicates the presence of liquid solution.

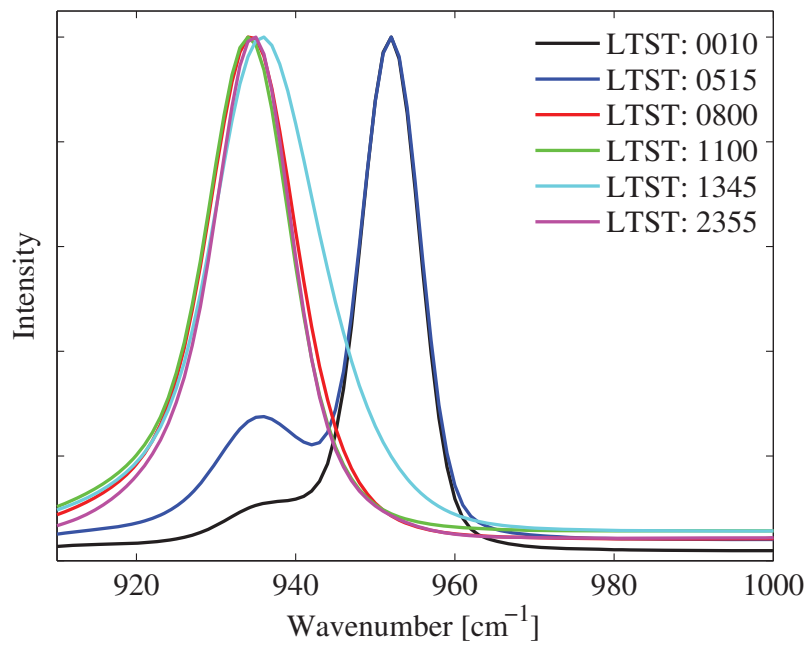

FIG. 6. As in Fig. 5, but for the perchlorate vibration band. In the spectrum taken at 08:00, the $\sim 954 \mathrm{~cm}^{-1}$ peak of crystalline $\mathrm{Ca}\left(\mathrm{ClO}_{4}\right)_{2} \cdot 4 \mathrm{H}_{2} \mathrm{O}$ shifted toward $\sim 936 \mathrm{~cm}^{-1}$, consistent with the presence of liquid solution. After the sample dries out at the end of the experiment, this peak does not shift back, indicating that it is not an unambiguous indicator for the presence of liquid brine.

Table 1. Gaussian Components of the O-H Stretching Band of the Reference Raman Spectra of $\mathrm{CA}\left(\mathrm{ClO}_{4}\right)_{2} \cdot 4 \mathrm{H}_{2} \mathrm{O}$, Water Ice, and Liquid Water (Left) (Zhang and Chan, 2003; Fischer et aL., 2014), As Well As of the Raman Spectra Shown in Figure 5 (Right)

\begin{tabular}{|c|c|c|c|c|c|c|c|c|c|c|c|c|c|c|c|c|c|}
\hline \multicolumn{6}{|c|}{ Reference Spectra } & \multicolumn{12}{|c|}{ First Experiment: Sol 19 Diurnal Cycle from Salt and Water Ice } \\
\hline \multicolumn{2}{|c|}{ Salt } & \multicolumn{2}{|c|}{ Ice } & \multicolumn{2}{|c|}{ Water } & \multicolumn{2}{|c|}{ LTST 0010} & \multicolumn{2}{|c|}{ LTST 0515} & \multicolumn{2}{|c|}{ LTST 0800} & \multicolumn{2}{|c|}{ LTST 1100} & \multicolumn{2}{|c|}{ LTST 1345} & \multicolumn{2}{|c|}{ LTST 2355} \\
\hline Peak & FWHM & Peak & FWHM & Peak & FWHM & Peak & FWHM & Peak & FWHM & Peak & FWHM & Peak & FWHM & Peak & FWHM & Peak & FWHM \\
\hline & & 3046 & 99 & & & & & 3068 & 143 & & & & & & & & \\
\hline & & 3115 & 57 & & & 3115 & 81 & 3122 & 60 & 3129 & 56 & & & & & & \\
\hline & & 3227 & 206 & 3230 & 217 & 3249 & 113 & 3210 & 148 & 3219 & 280 & 3282 & 268 & 3256 & 219 & & \\
\hline & & 3336 & 56 & & & & & & & & & & & & & 3311 & 271 \\
\hline & & 3399 & 140 & 3420 & 218 & 3437 & 147 & 3381 & 226 & 3434 & 224 & 3454 & 178 & 3495 & 249 & 3389 & 66 \\
\hline 3446 & 37 & & & & & 3437 & 27 & 3440 & 31 & & & & & & & 3456 & 38 \\
\hline 3471 & 20 & & & & & 3467 & 23 & 3470 & 24 & & & & & & & & \\
\hline 3487 & 24 & & & & & 3487 & 15 & 3488 & 16 & & & & & & & 3496 & 31 \\
\hline 3515 & 29 & & & & & 3509 & 25 & 3512 & 28 & & & & & & & 3520 & 19 \\
\hline & & & & 3540 & 206 & & & & & 3578 & 114 & 3582 & 125 & 3555 & 106 & & \\
\hline 3542 & 25 & & & & & 3536 & 23 & 3539 & 23 & & & & & & & 3543 & 17 \\
\hline 3564 & 70 & & & & & 3560 & 155 & 3569 & 122 & & & & & & & 3546 & 132 \\
\hline 3603 & 17 & & & & & 3602 & 13 & 3602 & 15 & & & & & & & & \\
\hline & & & & 3620 & 109 & & & & & & & & & & & & \\
\hline 3628 & 19 & & & & & 3630 & 18 & 3629 & 19 & & & & & & & & \\
\hline
\end{tabular}

Each column contains the wavenumber and FWHM of each spectral peak. The values of the spectral peaks and their FWHM are color-coded to indicate the presence of salt (black), water ice (blue), either water ice or liquid water (gray), and liquid water (red). The Gaussian components of the spectrum taken at 00:10, when the temperature is below the eutectic value, contain spectral peaks of hydrated perchlorate salt and water ice. In spite of the temperature being above the eutectic value and the image of the sample indicating that the ice starts to melt at 04:37, spectral peaks corresponding to liquid water are not observed at 05:15. The fact that the signal of the ice at the bottom of the sample is stronger at this time (the appearance of a shoulder caused by the $3068 \mathrm{~cm}^{-1}$ ice spectral peak and a general increase in intensity of all spectral peaks of ice, as shown in Fig. 5) provides indirect evidence that the ice has started to melt. The ice signal likely increases because the salt becomes more translucent when it absorbs liquid water. At 08:00 the Raman spectrum indicates the presence of liquid water unambiguously. The spectral peak at $\sim 3129 \mathrm{~cm}^{-1}$ indicates that water ice is still present, but by 11:00 this peak has disappeared. Evaporation of water causes the salt concentration of the solution to increase continuously until a salt crust forms at 13:45 (Fig. 7e). At this time, the Gaussian components still contain spectral peaks corresponding to brine because the signal from the thin crust is weak. Evaporation thickens the salt crust until crystalline calcium perchlorate hydrates dominate the spectrum at 23:55. The brine freezes below the salt crust when the temperature decreases below the eutectic value. The Gaussian components fit the full measured spectrum with accuracy $\bar{R}^{2} \geq 98 \%$. 

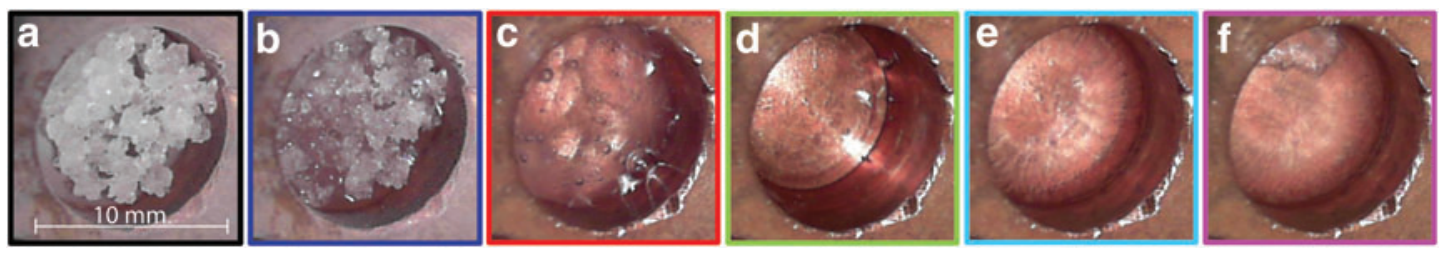

FIG. 7. Images of the sample color-coded according to the spectra shown in Figs. 5 and 6. (a) Salt on top of ice at the start of the experiment at 00:10 when the temperature is below the eutectic value. (b) Evidence for brine at 05:15, shortly after the eutectic temperature is exceeded. (c) Salt has completely dissolved, but water ice is still present at 08:00. (d) Only brine is present at 11:00. (e) Evidence for the presence of a salt crust at 13:45. The salt crust can be distinguished from the liquid by its different reflective properties. (f) Mainly crystalline salt hydrates with frozen brine below it at end of the diurnal cycle at 23:55.

values inferred from the Phoenix measurements (black curve), while the frost point temperature simulated by the MMEC (blue crosses) is higher than the values estimated (gray line) between 05:15 and 16:00 LTST (hereafter time always refers to local true solar time, LTST). This difference is caused by the fact that water ice and brine are significant sources of water vapor. Indeed, evaporation increases the frost point temperature as soon as brine forms. However, since the air around salt crystals in contact with the ice is always close to the saturation value, this difference does not affect our results significantly (Fischer et al., 2014). In particular, frost points simulated experimentally and modeled numerically start to diverge at 05:15, about $45 \mathrm{~min}$ after the first visual evidence for the formation of brine (details in Section 3). At that time, the flow of water vapor into the chamber was stopped, while the flow of dry $\mathrm{CO}_{2}$ was increased to mitigate the increase in frost point temperature. Still, evaporation from the brine and sublimation from the remaining water ice continued to increase the frost point until $\sim 08: 00$.

To investigate the sensitivity of the results of this first experiment to the initial conditions (e.g., sample state, local time), two additional experiments were conducted. In particular, the second experiment started with liquid brine, while the third experiment started with frozen brine. In the second experiment, $\mathrm{Ca}\left(\mathrm{ClO}_{4}\right)_{2}$ was mixed with distilled water at ambient conditions until the salt had been completely dissolved (the salt amount and sample characteristics were similar to those in the first experiment). The resulting solution was placed in the sample holder, the chamber pressure was adjusted to $800 \mathrm{~Pa}$, and the chamber air was replaced by $\mathrm{CO}_{2}$. Then, the temperature of the sample holder and the MMEC frost point temperature were adjusted continuously to follow those of the martian diurnal cycle between 13:45 and 06:30 shown in Fig. 2.

The third and fourth experiments started with frozen brine as the initial condition. In the third experiment, brine was produced as in the second experiment. Then, the temperature of the solution was lowered rapidly to values $<150 \mathrm{~K}$ to freeze the brine and mitigate evaporation. Then, the chamber pressure was adjusted to $800 \mathrm{~Pa}$, and the chamber air was replaced by $\mathrm{CO}_{2}$. The temperature was kept below $150 \mathrm{~K}$ for at least $3.5 \mathrm{~h}$ to ensure freezing of the sample. Then, the simulation of the diurnal cycle started, following the temperature and frost point values shown in Fig. 3. In the fourth experiment, the MMEC atmosphere was kept saturated by the MMEC control system throughout the experiment to simulate the humidity above the ground ice exposed underneath the Phoenix lander. In this experiment, the temperature of the sample was forced to follow that corresponding to the diurnal cycle on the strut shown in Fig. 4.
In all experiments, the temperature of the sample holder was adjusted in $1 \mathrm{~K}$ increments to force it to follow the martian diurnal cycle. The sample temperature, the chamber pressure, and the chamber frost point temperature were recorded at $1 \mathrm{~Hz}$. Raman spectra of the sample and color images were acquired every $10 \mathrm{~min}$. Gaussian decomposition of each spectrum was conducted during the entire diurnal cycles to search for changes in the phase of the samples. The wavenumber and full width half maximum (FWHM) of various spectral peaks are used to determine the phase of the samples by comparing them with reference values for crystalline perchlorate (salt), water ice, and liquid water (Zhang and Chan, 2003; Fischer et al., 2014).

Since our study focuses on the formation of bulk quantities of brine, images in the visible range of the spectrum (color images) are used as supporting evidence for the detection of the liquid phase. This is necessary because when brine starts to form the sample is heterogeneous, containing brine, crystalline salt, and water ice. Thus, spectral features of one particular component of the mixture might dominate the Raman spectrum because the diameter of the sample holder $(\sim 10 \mathrm{~mm})$ is larger than that of the laser beam $(\sim 3 \mathrm{~mm})$ of the Raman spectrometer.

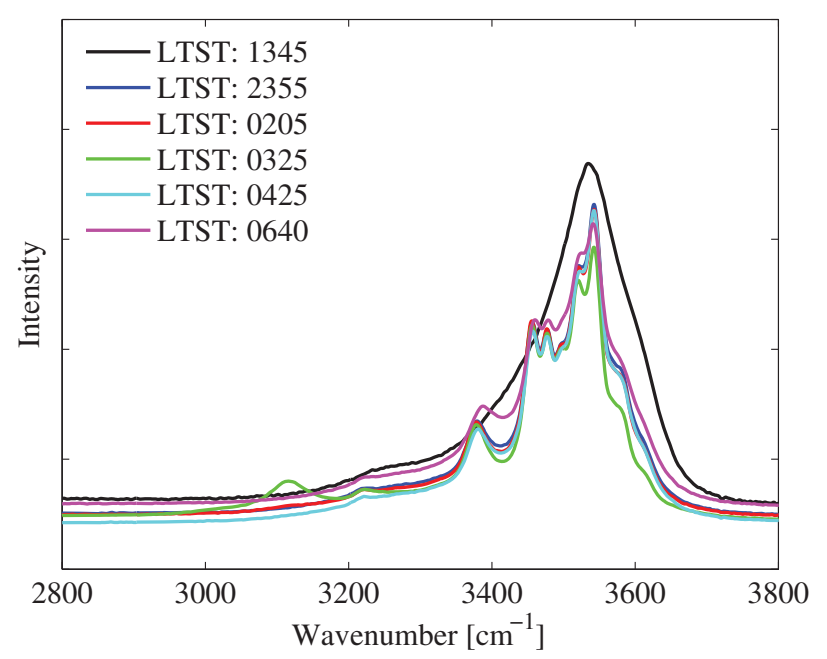

FIG. 8. Raman spectra in the $\mathrm{O}-\mathrm{H}$ stretching band throughout the partial diurnal cycle shown in Fig. 2 (second experiment). Gaussian components of each spectrum are shown in Table 2 . A change from the smooth curve representing salt-saturated brine (black) to the narrow peaks indicating crystalline salt is observed. 
Table 2. As in Table 1, BUt for the SECOnd Experiment

\begin{tabular}{|c|c|c|c|c|c|c|c|c|c|c|c|c|c|c|c|c|c|}
\hline \multicolumn{6}{|c|}{ Reference Spectra } & \multicolumn{12}{|c|}{ Second Experiment: Sol 19-20 Partial Diurnal Cycle from Liquid Brine } \\
\hline \multicolumn{2}{|c|}{ Salt } & \multicolumn{2}{|c|}{ Ice } & \multicolumn{2}{|c|}{ Water } & \multicolumn{2}{|c|}{ LTST 1345} & \multicolumn{2}{|c|}{ LTST 2355} & \multicolumn{2}{|c|}{ LTST 0205} & \multicolumn{2}{|c|}{ LTST 0325} & \multicolumn{2}{|c|}{ LTST 0425} & \multicolumn{2}{|c|}{ LTST 0640} \\
\hline Peak & FWHM & Peak & FWHM & Peak & FWHM & Peak & FWHM & Peak & FWHM & Peak & FWHM & Peak & FWHM & Peak & FWHM & Peak & FWHM \\
\hline & & 3046 & 99 & & & & & & & & & & & & & & \\
\hline & & 3115 & 57 & & & & & & & & & 3114 & 59 & & & & \\
\hline & & 3227 & 206 & 3230 & 217 & & & 3223 & 47 & 3222 & 27 & 3223 & 24 & 3222 & 30 & 3224 & 30 \\
\hline & & 3336 & 56 & & & 3328 & 250 & 3387 & 340 & 3387 & 376 & 3355 & 433 & 3388 & 359 & 3395 & 338 \\
\hline & & 3399 & 140 & 3420 & 218 & 3413 & 83 & 3387 & 56 & 3387 & 58 & 3383 & 52 & 3388 & 57 & 3395 & 61 \\
\hline 3446 & 37 & & & & & & & 3459 & 37 & 3457 & 33 & 3458 & 35 & 3459 & 37 & 3464 & 43 \\
\hline 3471 & 20 & & & & & & & 3478 & 12 & 3478 & 12 & 3478 & 12 & 3479 & 13 & 3481 & 12 \\
\hline 3487 & 24 & & & & & & & 3496 & 25 & 3495 & 24 & 3496 & 25 & 3496 & 23 & 3497 & 23 \\
\hline 3515 & 29 & & & & & & & 3520 & 23 & 3520 & 24 & 3520 & 23 & 3520 & 25 & 3520 & 28 \\
\hline & & & & 3540 & 206 & 3539 & 136 & & & & & & & & & & \\
\hline 3542 & 25 & & & & & & & 3543 & 21 & 3543 & 21 & 3543 & 21 & 3543 & 21 & 3543 & 21 \\
\hline 3564 & 70 & & & & & & & 3568 & 49 & 3569 & 46 & 3573 & 45 & 3567 & 52 & 3558 & 60 \\
\hline 3603 & 17 & & & & & & & 3607 & 65 & 3608 & 57 & 3617 & 32 & 3603 & 75 & 3591 & 84 \\
\hline & & & & 3620 & 109 & & & & & & & & & & & & \\
\hline 3628 & 19 & & & & & & & & & & & & & & & & \\
\hline
\end{tabular}

The Gaussian decomposition of the spectrum at 13:45 shows a liquid water peak at $3539 \mathrm{~cm}^{-1}$, indicating that the sample is brine when the salt crust forms (see Fig. 10a). Another peak at $3328 \mathrm{~cm}^{-1}$ seems to indicate the presence of ice, but this is unlikely because the temperature at 13:45 is the warmest of Sol 19, about $60 \mathrm{~K}$ above the eutectic point, and the sample was initially prepared as a saturated solution. A peak at a lower wavenumber (closer to the $3230 \mathrm{~cm}^{-1}$ peak in the water reference) with a slightly different FWHM leads to a similar accuracy for the complete decomposition. We believe that this is caused by inaccuracies in peak positions when wide FWHM values occur in the Gaussian decomposition, as it is the case for the $3328 \mathrm{~cm}^{-1}$ peak in this decomposition. Ambiguities in the detection of phase changes using Gaussian decomposition will be described in more detail in a future study. Only salt and ice peaks are present at 23:55 because most of the water in the sample has evaporated and the remaining solution is frozen (see Fig. 10b). The Gaussian decomposition does not change until 03:25, when an additional ice peak at $3114 \mathrm{~cm}^{-1}$ appears (see Fig. 8). At this time the frozen solution in the sample is whitish and opaque, similar to the material found in the Dodo-Goldilocks trench by the Phoenix lander (Fig. S2). At 04:25 the peak at $3114 \mathrm{~cm}^{-1}$ and the white color disappear (Fig. 10e). This happens when the temperature exceeds the eutectic value. At 06:40, about $2 \mathrm{~h}$ after exceeding the eutectic temperature, no peak indicating brine is detected, suggesting that the frozen solution is whitish because it is nearly salt-saturated. Most of the water substance has either evaporated or sublimated, and not enough water is available to form brine in a subsequent diurnal cycle.

\section{Results}

\subsection{First experiment: diurnal cycle of salt deposited on ice at martian polar surface conditions}

In the first experiment, the Gaussian decomposition of the Raman spectra taken at 00:10 (Figs. 5 and 6), when the temperature is below the eutectic value (Fig. 1), contains spectral peaks that indicate the presence of crystalline $\mathrm{Ca}\left(\mathrm{ClO}_{4}\right)_{2}$ hydrates and water ice (Table 1). At 05:15, the spectral peaks of crystalline $\mathrm{Ca}\left(\mathrm{ClO}_{4}\right)_{2}$ hydrates are still present, but the signal from water ice is stronger than at $00: 10$, with the $3068 \mathrm{~cm}^{-1}$ spectral peak of ice appearing and the other spectral peaks of ice intensifying (Fig. 5 and Table 1). At this time, spectral peaks indicating the presence of liquid water are not observed, even though the first visual evidence (color image) for the formation of brine occurs at 04:37, about $5 \mathrm{~min}$ after the temperature exceeds the eutectic value for $\mathrm{Ca}\left(\mathrm{ClO}_{4}\right)_{2}$ (Fig. 1). This occurs because, when ice starts to melt, $\mathrm{Ca}\left(\mathrm{ClO}_{4}\right)_{2}$ hydrates absorb meltwater (Fig. 7b) and become more translucent, increasing the signal of the ice below the salt. The heterogeneity of the sample in combination with the fixed position of the Raman laser may also lead to slight variations in the time when the liquid water peaks start to appear. At 08:00, the decomposition of the spectrum indicates the presence of brine; in particular, the $3578 \mathrm{~cm}^{-1}$ spectral peak (Table 1) indicates the presence of brine unambiguously, which is consistent with the shift in the perchlorate peak from 954 to $936 \mathrm{~cm}^{-1}$ (Gough et al.,
2011) (Fig. 6). The $3129 \mathrm{~cm}^{-1}$ peak at $08: 00$ indicates that ice (Table 1) is also present. No signal of crystalline $\mathrm{Ca}\left(\mathrm{ClO}_{4}\right)_{2}$ hydrates exists at this time, which is consistent with the lack of salt crystals in the image of the sample (Fig. 7c). By 11:00, all water ice peaks have disappeared, and the entire sample is liquid (Fig. 7d). As the temperature rises, water evaporation

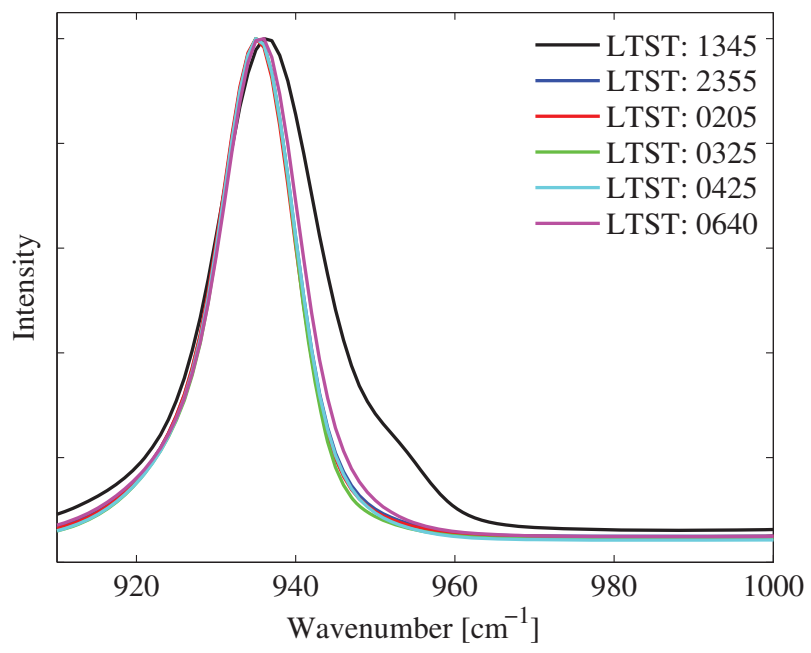

FIG. 9. As in Fig. 8, but for the perchlorate vibration band. This experiment starts with brine and ends with hydrated calcium perchlorate. The perchlorate peak remains at $936 \mathrm{~cm}^{-1}$ during the entire experiment. 

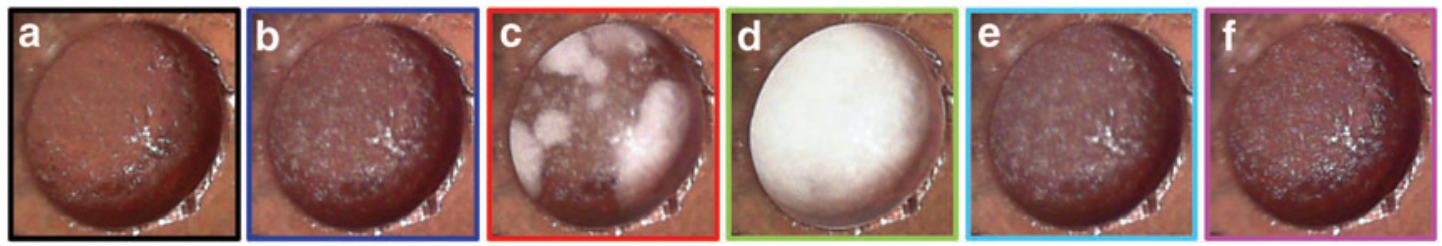

FIG. 10. Images of the sample color-coded according to spectra shown in Figs. 8 and 9. (a) Evaporation of water causes a salt crust to start to form at 13:45. (b) Mainly crystalline perchlorate hydrates at the end of the diurnal cycle at 23:55. (c) The frozen brine starts to become white at 02:05. (d) Whitish frozen brine at 03:25, similar to the material found in the Dodo-Goldilocks trench. (e) The sample becomes translucent again after the eutectic temperature is exceeded at 04:25 and the remaining ice partially melts. (f) Wet calcium perchlorate hydrates at 06:40, with no evidence for brine. The fact that brine is not observed even $2 \mathrm{~h}$ after the eutectic temperature has been exceeded indicates that the sample lacks bulk water (frozen brine at 03:25 is whitish because it is nearly salt-saturated and therefore lacks bulk water).

increases the concentration of the solution. At 13:45, a thin salt crust formed on the top of the sample, indicating that the brine solution became at least partially salt-saturated (Fig. 7e). The Gaussian decomposition of the spectrum taken at this time contains only the spectral peaks indicative of brine because the signal from the thin crust is insignificant. As the experiment progresses, evaporation continues and the salt crust thickens. The Gaussian decomposition of the spectrum taken at 23:55, when the temperature is already below the eutectic value (Fig. 1), indicates the presence of a salt crust and frozen brine below it (Table 1). At this time, the sample was composed almost entirely of crystalline salt hydrates because most of the bulk water originally in the sample had been lost by sublimation and evaporation (Fig. 7f). Any remaining solution below was saturated.

\subsection{Second experiment: effect of a subsequent diurnal cycle}

To investigate the sensitivity of the results of the experiments to initial conditions (sample state) and to investigate what happens in successive diurnal cycles, a second experiment was performed starting with brine at 13:45 (Fig. 2), the time that the salt crust started to form in the first experiment, and ending on the next sol at 06:30. As explained next, evaporation of the initial brine during the afternoon hours caused the sample to dry substantially and to become mostly crystalline salt hydrates by midnight. The Raman spectrum of the $\mathrm{O}-\mathrm{H}$ region (Fig. 8) shows this change by the transformation of the smooth curve representing salt-saturated brine at 13:45 to the narrow peaks indicating the presence of crystalline salt by midnight (Table 2). The perchlorate peak of the spectrum does not change considerably throughout this transformation (Fig. 9), indicating that the O-H spectrum is a better indicator for phase changes of the sample. Continued cooling of the sample below the eutectic temperature in this second experiment resulted in whitish solid material (Figs. 10b-10d), similar to the material found by the Phoenix lander in a shallow trench (Rennó et al., 2009; Cull et al., 2010a). Brine was not detected when the temperature exceeded the eutectic value on the next sol (Table 2; Figs. 10e-10f), indicating that the sample had extremely low water content.

\subsection{Third experiment: diurnal cycle of initially frozen brine at martian polar surface conditions}

To further analyze the impact of the initial state of the sample on the results, a third experiment starting with frozen brine instead of salt on top of ice (first experiment) or brine (second experiment) was conducted. This experiment covered the portion of the Sol 19 diurnal cycle between 04:00 and 15:30 (Fig. 3). This third experiment with frozen brine as the initial sample might be indicative of the evolution of the material unveiled at the Dodo-Goldilocks trench, while the first experiment with salt on top of ice as the initial sample represents the evolution of a soil salt crust covered by snow (Whiteway et al., 2009) or frost (Smith et al., 2009). The evolution of the sample throughout diurnal cycles is similar in the first and third experiments (Fig. 11 and Table 3). However, a significant difference between them is that, at the beginning of the third experiment, when the temperature was still below the eutectic value and brine (liquid) was not present in the sample, the perchlorate peak is now located at $936 \mathrm{~cm}^{-1}$, suggesting a different hydration state (Fig. 12). Consequently, in this case, the perchlorate peak in the Raman spectrum at $936 \mathrm{~cm}^{-1}$ is the result of the presence of only crystalline salt hydrates, indicating that this peak is an ambiguous indicator of the presence of brine. Throughout the diurnal cycle, the sample underwent similar changes as those observed in the first experiment: the frozen brine melted when the eutectic temperature was exceeded, and evaporation of water from the brine produced a salt crust on the top of the sample (Fig. 13). However, both brine

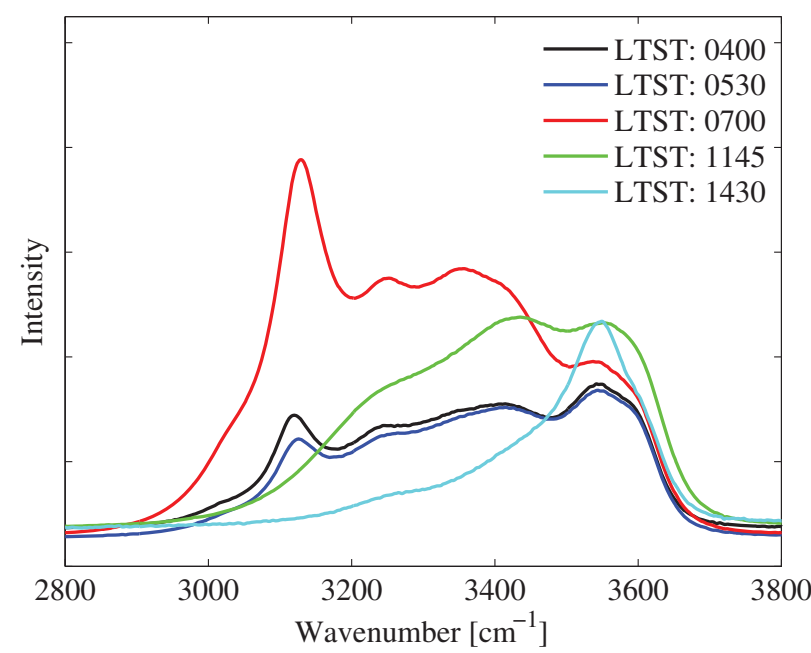

FIG. 11. Raman spectra in the O-H stretching band throughout the partial diurnal cycle shown in Fig. 3 (third experiment). Gaussian components of each spectrum are shown in Table 3. 
TABle 3. As in TABle 1, BUt for the Third ExPeriment

\begin{tabular}{|c|c|c|c|c|c|c|c|c|c|c|c|c|c|c|c|}
\hline \multicolumn{6}{|c|}{ Reference Spectra } & \multicolumn{10}{|c|}{ Third Experiment: Sol 19 Partial Diurnal Cycle from Frozen Brine } \\
\hline \multicolumn{2}{|c|}{ Salt } & \multicolumn{2}{|c|}{ Ice } & \multicolumn{2}{|c|}{ Water } & \multicolumn{2}{|c|}{ LTST 0400} & \multicolumn{2}{|c|}{ LTST 0530} & \multicolumn{2}{|c|}{ LTST 0700} & \multicolumn{2}{|c|}{ LTST 1145} & \multicolumn{2}{|c|}{ LTST 1430} \\
\hline Peak & FWHM & Peak & FWHM & Peak & FWHM & Peak & FWHM & Peak & FWHM & Peak & FWHM & Peak & FWHM & Peak & FWHM \\
\hline & & 3046 & 99 & & & 3051 & 128 & 3053 & 130 & 3075 & 156 & & & & \\
\hline & & 3115 & 57 & & & 3119 & 56 & 3123 & 57 & 3128 & 61 & & & & \\
\hline & & 3227 & 206 & 3230 & 217 & 3256 & 247 & 3264 & 265 & 3229 & 189 & 3274 & 260 & 3274 & 248 \\
\hline & & 3336 & 56 & & & & & & & 3346 & 50 & & & & \\
\hline & & 3399 & 140 & 3420 & 218 & 3424 & 159 & 3428 & 156 & 3407 & 194 & 3455 & 187 & 3498 & 240 \\
\hline 3446 & 37 & & & & & & & & & & & & & & \\
\hline 3471 & 20 & & & & & & & & & & & & & & \\
\hline 3487 & 24 & & & & & & & & & & & & & & \\
\hline 3515 & 29 & & & & & & & & & & & & & & \\
\hline & & & & 3540 & 206 & 3559 & 119 & 3561 & 123 & 3573 & 113 & 3584 & 119 & 3558 & 107 \\
\hline 3542 & 25 & & & & & & & & & & & & & & \\
\hline 3564 & 70 & & & & & & & & & & & & & & \\
\hline 3603 & 17 & & & & & 3607 & 40 & 3608 & 41 & & & & & & \\
\hline & & & & 3620 & 109 & & & & & & & & & & \\
\hline 3628 & 19 & & & & & & & & & & & & & & \\
\hline
\end{tabular}

At 04:00 the spectrum contains ice and salt peaks, as well as a single water peak at $3559 \mathrm{~cm}^{-1}$. The presence of the water peak might be caused by small amounts of brine in the ice even at temperatures far below the eutectic value. This behavior was also observed at the end of the fourth experiment, when brine remained liquid even after the sample was kept below the eutectic temperature for at least 30 min (Table 4). The spectral decomposition has barely changed by 05:30, when the eutectic temperature has been exceeded and brine starts to become visible in the image (Fig. 13b). At 07:00 the salt peak disappears, and only water and ice peaks are left, consistent with Fig. 13c. At 11:45 the ice has melted completely, and the ice peaks have disappeared from the spectrum. Only liquid water peaks remain until the onset of a crust formation at 14:30. The onset of brine and crust formation occurs 45 min later than in the first experiment.

and the salt crust formed about $45 \mathrm{~min}$ later in the third experiment than in the first.

\subsection{Fourth experiment: diurnal cycle of initially frozen brine at the environmental conditions of the Phoenix strut}

A fourth experiment was conducted to simulate the full Sol 19 diurnal cycle on the Phoenix strut at about $0.5 \mathrm{~m}$ above the ground (Figs. 14-16 and Table 4), where spheroids were ob-

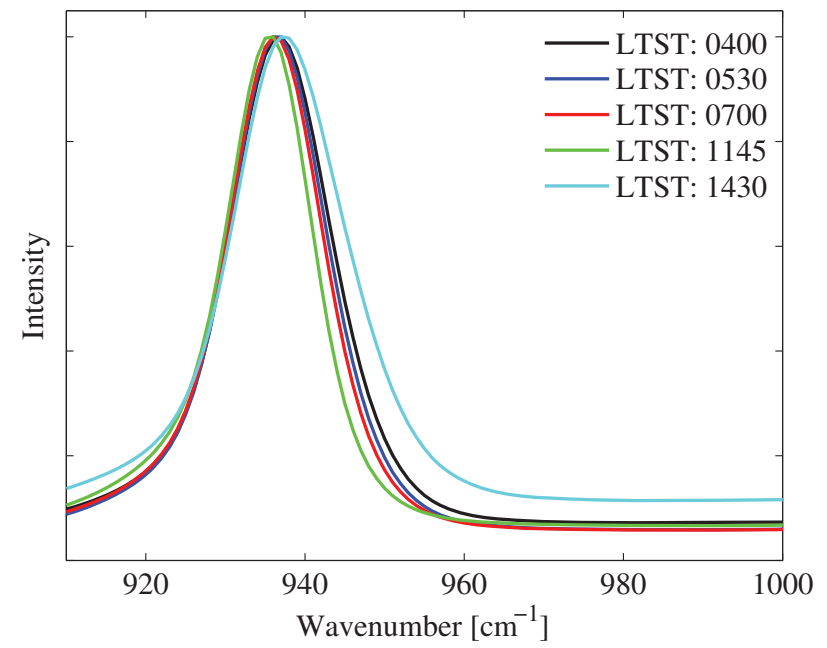

FIG. 12. As in Fig. 11, but for the perchlorate vibration band. The perchlorate peak at $936 \mathrm{~cm}^{-1}$ is at a similar location for both, the mix of water ice and salt (frozen brine) (black curve) and brine (green and cyan curves), indicating that it is not an unambiguous indicator of brine. served. This fourth experiment started at midnight (Fig. 4) with frozen brine that we hypothesize to be representative of the material splashed on the Phoenix lander strut during landing. The decomposition of the Raman spectrum of frozen brine at 12:15 (Fig. 14), when the temperature was still below the eutectic point, indicates the presence of ice and salt peaks (Table 4). Similar to the peak observed in the third experiment and shown in Fig. 12, the perchlorate peak for the frozen brine is at $936 \mathrm{~cm}^{-1}$ (Fig. 15). The first visual evidence of melting occurs at 01:35 (Fig. 16b), $5 \mathrm{~min}$ after the eutectic temperature is exceeded. However, changes in the Raman spectrum appear only after $\sim 04: 30$, when the ice peak at $\sim 3120 \mathrm{~cm}^{-1}$ starts to disappear as shown in Fig. 14. This might be the result of a lower rate of temperature increase (Fig. 4) in this experiment than in the previous experiments (Fig. 2). The ice peaks are completely gone by $12: 35$, with only the liquid water peaks remaining. The spectrum does not change from 17:15 until the end of the experiment (Table 4), with the sample remaining liquid until midnight, despite the sample temperature being below the eutectic value during the last $\sim 30 \mathrm{~min}$ of the experiment (Fig. 4). Brine persisted longer than in the previous experiments because the temperature at the strut at $0.5 \mathrm{~m}$ above the surface was below the eutectic value for only $\sim 3 \mathrm{~h}$, compared to $\sim 7 \mathrm{~h}$ at the ground (Fig. 1). In addition, the lower maximum temperature reduced loss of water by evaporation.

\section{Discussion}

Our results show that, when water ice is in contact with $\mathrm{Ca}\left(\mathrm{ClO}_{4}\right)_{2}$ salt, either unmixed or as in a frozen brine, (liquid) brine forms within a few minutes in the unmixed case and within $\sim 45 \mathrm{~min}$ in the case of frozen brine of the eutectic 

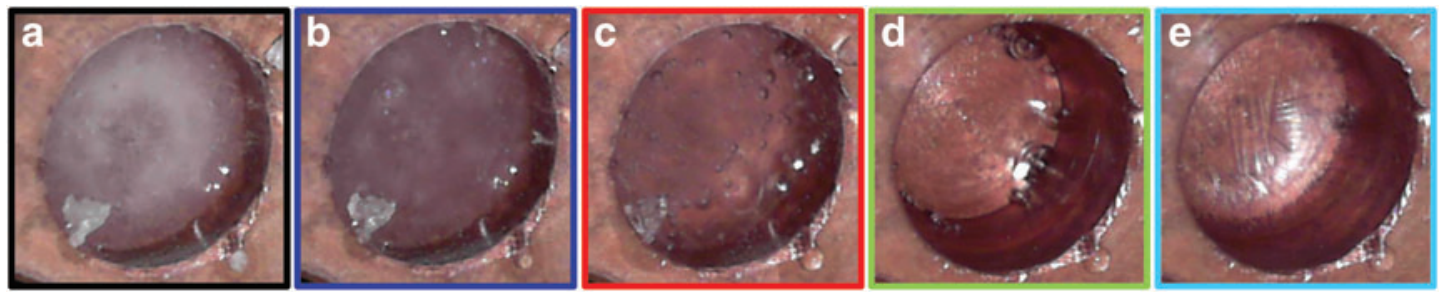

FIG. 13. Images of the sample color-coded according to the spectra shown in Figs. 11 and 12. (a) Frozen mix of water ice and perchlorate salt at 04:00 at $195 \mathrm{~K}$ after preparing the sample at $150 \mathrm{~K}$. The darker color compared to the whitish frozen brine in the second experiment shown in Fig. 10d is likely due to a larger water content in the frozen mix, consistent with the observation of brine later in the diurnal cycle when the eutectic temperature is exceeded. (b) Brine forms at 05:30, after the temperature exceeds the eutectic value. (c) Brine on top of frozen brine at 07:00. (d) Brine only at 11:45. (e) Start of crust formation at 14:30.

temperature being exceeded. Then, as the temperature increases during the diurnal cycle, evaporation increases the concentration of the solution, causing a salt crust to form on the top of the sample. Due to the limited penetration depth of the Raman laser, the exact time when a liquid phase ceases to exist in the sample cannot be measured unambiguously. Taking the first experiment as an example, this occurs because the position of the liquid water peak at $3555 \mathrm{~cm}^{-1}$ does not change abruptly between 13:45 and the end of the experiment (Fig. 5; Table 1). Electrical conductivity or permittivity measurements may be able to determine the exact time that brine forms (Zandonadi et al., 2015; Heinz et al., 2016). As evaporation thickens the salt crust, the $3555 \mathrm{~cm}^{-1}$ spectral peak indicating the presence of liquid water transitions smoothly into nearby peaks at 3543 and $3546 \mathrm{~cm}^{-1}$ indicating the presence of crystalline $\mathrm{Ca}\left(\mathrm{ClO}_{4}\right)_{2}$ hydrates. However, our results suggest that, while the temperature was above the eutectic value for about $17 \mathrm{~h}$ on Sol 19 (Fig. 1), brine could have formed and persisted in the DodoGoldilocks trench as long as enough water ice was present to compensate for evaporation. Our analysis also indicated that brine formed at about 04:37 (i.e., minutes after the ground temperature exceeded the eutectic value) and froze at about 22:20 (when the ground temperature decreased below the eutectic value).

Results of experiments with a soil-salt-ice mixture indicate that the presence of a soil causes a delay in brine formation.

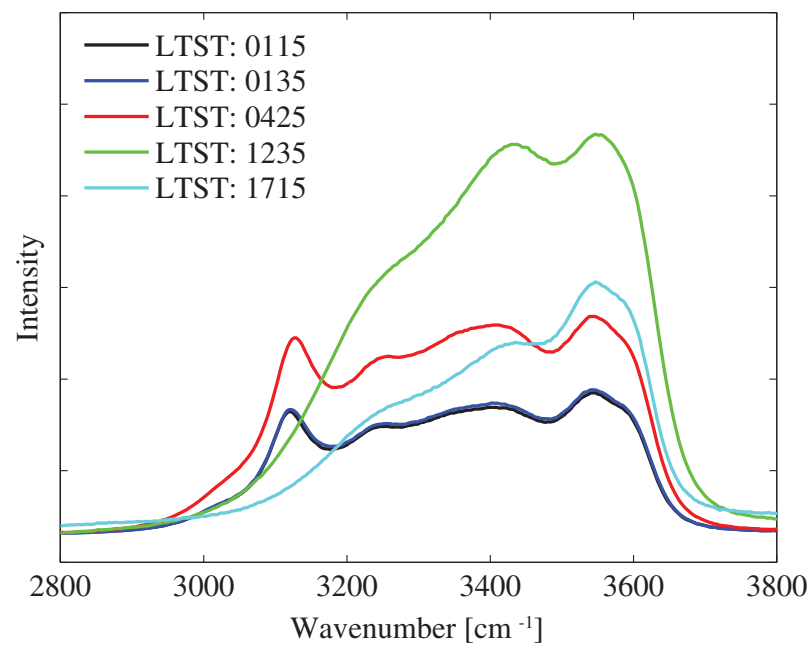

FIG. 14. Raman spectra in the $\mathrm{O}-\mathrm{H}$ stretching band throughout the diurnal cycle shown in Fig. 4 (fourth experiment). Gaussian components of each spectrum are shown in Table 4.
Results of these experiments will be the subject of a future article because of the added complexity to the observed Raman spectra.

Brine formation could also occur between polar and midlatitude regions, where frost and snow are seasonally deposited on saline soils (Whiteway et al., 2009; Martínez et al., 2012); water ice is seasonally present in the shallow subsurface (Cull et al., 2010b); and temperatures exceed the eutectic value during a significant fraction of the sol (from minutes to hours depending on the location and time of the year) (Möhlmann, 2011; Fischer et al., 2014; Nuding et al., 2014). Therefore, our results suggest that brine could form in the martian polar region on seasonal timescales and persist for as long as the temperature remains above the eutectic value during diurnal cycles because the melting of water ice could compensate for evaporation.

Water ice is unlikely to be present in the shallow subsurface of midlatitudes and equatorial regions because it is not thermodynamically stable in these places (Mitrofanov et al., 2002; Schorghofer and Aharonson, 2005). However, frozen brine could be stable in the shallow subsurface of midlatitude regions, and brine could form temporally if the temperature exceeds the eutectic value. In addition, thin layers of frost are possible on polar-facing slopes of those regions throughout the day (Vincendon et al., 2010), as well as on flat terrains at night (Wall, 1981; Möhlmann, 2008). Under these conditions, frost in contact with $\mathrm{Ca}\left(\mathrm{ClO}_{4}\right)_{2}$ salt could produce brine, but only in

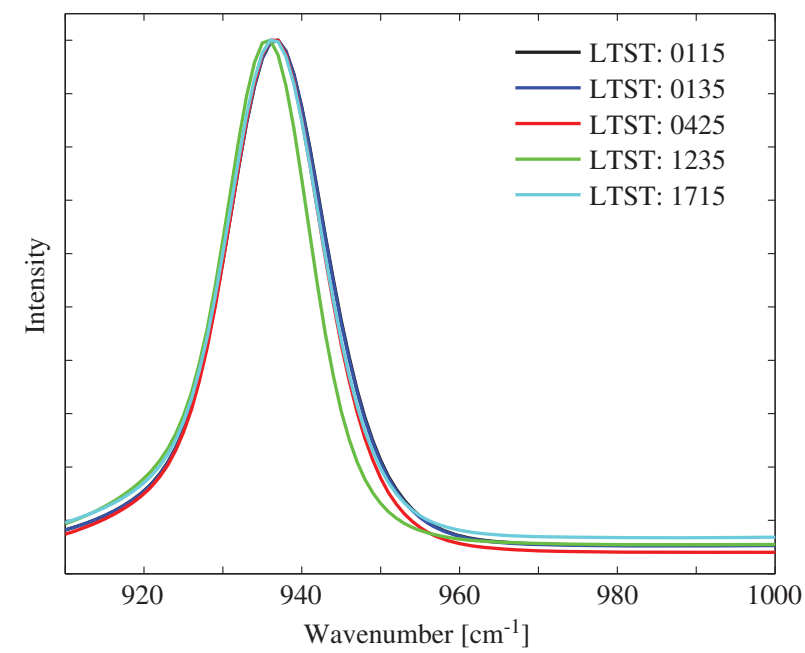

FIG. 15. As in Fig. 14, but for the perchlorate vibration band. The perchlorate peak is at $936 \mathrm{~cm}^{-1}$ for both, the mix of water ice and salt and brine, similar to the peak shown in Fig. 12. 

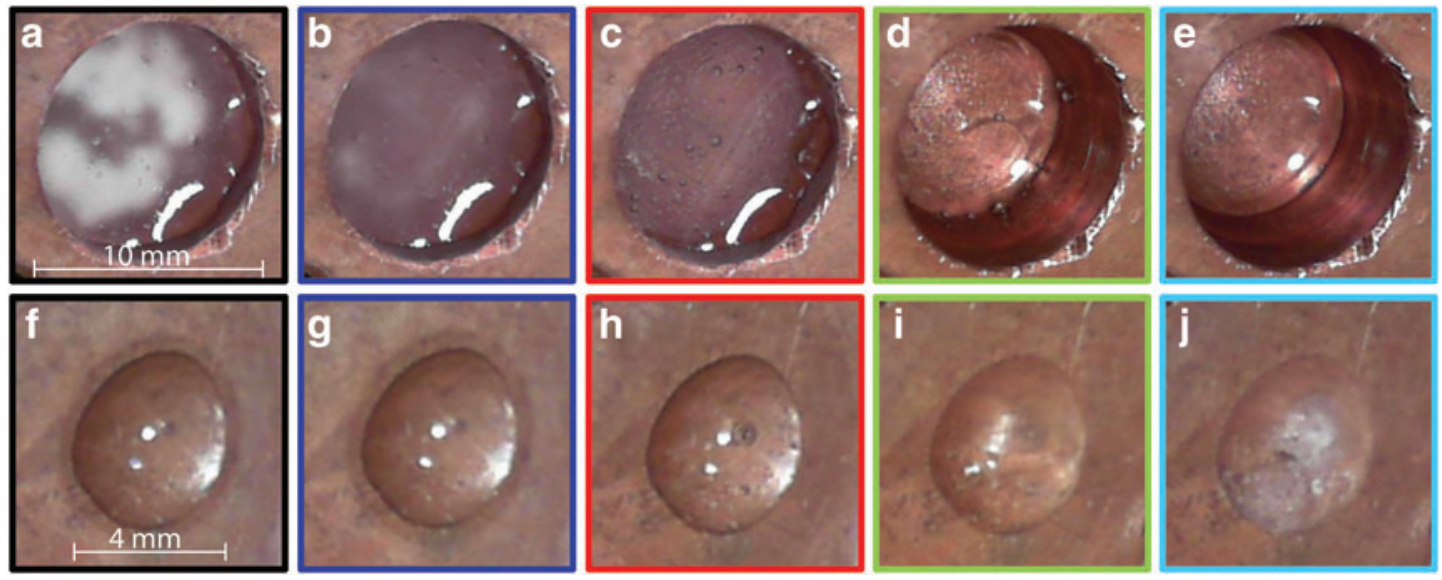

FIG. 16. Images of the sample (a-e) and of a spheroid of the same composition ( $\mathrm{f}-\mathrm{j})$, similar to those observed on the Phoenix strut, color-coded to represent the times when the Raman spectra were taken (Figs. 14 and 15). (a) Frozen mix of water ice and perchlorate salt at 01:15. Translucent areas in the sample compared to the completely whitish frozen brine in Fig. 10d are likely because of the larger water content of the frozen mix. (b) Onset of liquefaction at 01:35 after the temperature exceeds the eutectic value. (c) Brine and ice at 04:25, with the Raman signal indicating only the presence of ice (Table 4). (d-e) Only brine remains between 12:35 and 17:15. (f) Frozen spheroid at 01:15. (g) No clear sign of melting is observed at 01:35, after the eutectic temperature is exceeded. (h) Melting of the spheroid is indicated by bubble formation and movement. (i) Crust formation on the spheroid at 12:35. This indicates higher evaporation on the spheroid than on the sample holder likely because of the spheroid's larger surface-area-to-volume ratio. (j) Dry spheroid at 17:15.

the short time interval during which the ground temperature is above the eutectic value and the frost has not completely sublimated away.

$\mathrm{Ca}\left(\mathrm{ClO}_{4}\right)_{2}$ salt was detected at the Mars Science Laboratory landing site at Gale Crater (Glavin et al., 2013), where evidence for nighttime formation of frost a few tenths of a micrometer thick (Martínez et al., 2015; Savijärvi et al., 2015) has been reported. However, frost can form at Gale only between 04:00 and 06:00, when the ground temperature is below the eutectic point. This thin layer of frost would have likely sublimated away by $\sim 07: 00$, when the ground temperature first exceeds the eutectic value on the sols when

Table 4. As in Table 1, But for the Fourth Experiment

\begin{tabular}{|c|c|c|c|c|c|c|c|c|c|c|c|c|c|c|c|}
\hline \multicolumn{6}{|c|}{ Reference Spectra } & \multicolumn{10}{|c|}{ Fourth Experiment: Sol 19 Diurnal Cycle of the Strut Temperature } \\
\hline \multicolumn{2}{|c|}{ Salt } & \multicolumn{2}{|c|}{ Ice } & \multicolumn{2}{|c|}{ Water } & \multicolumn{2}{|c|}{ LTST 0115} & \multicolumn{2}{|c|}{ LTST 0135} & \multicolumn{2}{|c|}{ LTST 0425} & \multicolumn{2}{|c|}{ LTST 1235} & \multicolumn{2}{|c|}{ LTST 1715} \\
\hline Peak & FWHM & Peak & FWHM & Peak & FWHM & Peak & FWHM & Peak & FWHM & Peak & FWHM & Peak & FWHM & Peak & FWHM \\
\hline & & 3046 & 99 & & & 3066 & 142 & 3069 & 145 & 3073 & 149 & & & & \\
\hline & & 3115 & 57 & & & 3119 & 57 & 3121 & 58 & 3125 & 61 & & & & \\
\hline & & 3227 & 206 & 3230 & 217 & 3213 & 162 & 3214 & 157 & 3216 & 157 & 3278 & 163 & 3289 & 262 \\
\hline & & 3336 & 56 & & & & & & & & & & & & \\
\hline & & 3399 & 140 & 3420 & 218 & 3407 & 275 & 3406 & 274 & 3406 & 273 & 3454 & 181 & 3449 & 164 \\
\hline 3446 & 37 & & & & & & & & & & & & & & \\
\hline 3471 & 20 & & & & & & & & & & & & & & \\
\hline 3487 & 24 & & & & & & & & & & & & & & \\
\hline 3515 & 29 & & & & & & & & & & & & & & \\
\hline & & & & 3540 & 206 & & & & & & & 3582 & 121 & 3572 & 122 \\
\hline 3542 & 25 & & & & & 3544 & 72 & 3544 & 72 & 3545 & 73 & & & & \\
\hline 3564 & 70 & & & & & & & & & & & & & & \\
\hline 3603 & 17 & & & & & 3600 & 63 & 3601 & 64 & 3601 & 67 & & & & \\
\hline & & & & 3620 & 109 & & & & & & & & & & \\
\hline 3628 & 19 & & & & & & & & & & & & & & \\
\hline
\end{tabular}

The decomposition of the frozen mix at 01:15 contains ice and salt peaks. Despite exceeding the eutectic temperature at 01:30, spectral changes have not occurred by 04:25. This might be explained by a lower rate of temperature increase after crossing the eutectic temperature (Fig. 4) than that occurring on the ground (Fig. 2). The ice peaks start to disappear after $\sim 04: 30$ and are completely gone by 12:35, with only the liquid water peaks remaining. This change is also visible in Fig. 16d, showing the remaining ice melting. The spectrum does not change from 17:15 until the end of the experiment, with the sample staying liquid even during the last 30 min of the experiment when the temperature decreases below the eutectic value. In this experiment, a salt crust does not form on the sample because the lower maximum temperature and near-saturated air mitigate evaporation. 
frost is predicted (Martínez et al., 2015). In addition, the solubility of $\mathrm{Ca}\left(\mathrm{ClO}_{4}\right)_{2}$ salts in ice of a thickness of a few tenths of a micrometer is not known. This indicates that brine is unlikely to form at the surface of Gale Crater.

\section{Conclusion}

The Phoenix lander discovered water ice (Smith et al., 2009) and salts such as $\mathrm{Ca}\left(\mathrm{ClO}_{4}\right)_{2}$ with a eutectic temperature lower than the maximum diurnal ground temperature at its landing site (Hecht et al., 2009). In addition, Phoenix found indirect evidence for frozen brine in a shallow trench excavated by the Phoenix robotic arm on Sols 18-19 (Rennó et al., 2009; Cull et al., 2010a). Here, we show that, at Phoenix landing site environmental conditions, brine forms minutes after the eutectic temperature is exceeded and stays liquid for $\sim 18 \mathrm{~h}$ while the temperature is above the eutectic value if enough water ice is present to compensate for some of the water loss by evaporation. Furthermore, our experiments' results indicate that the spheroids observed on a strut of the Phoenix lander early in the mission might have remained liquid for most of the diurnal cycle $(\sim 22 \mathrm{~h})$ if the melting of frozen brine splashed during the landing formed them. Thus, the martian polar region may temporarily have one of the essential ingredients to be a habitat for microorganisms that thrive in brine (Boetius and Joye, 2009).

\section{Acknowledgments}

Funding for this project was provided by the NASA Astrobiology Program: Exobiology and Evolutionary Biology Award \#09-EXOB09-0050. Our experimental data are available upon request.

\section{Disclosure Statement}

No competing financial interests exist.

\section{References}

Boetius, A. and Joye, S. (2009) Thriving in salt. Science 324:1523-1525.

Boynton, W.V., Feldman, W.C., Squyres, S.W., Prettyman, T.H., Bruckner, J., Evans, L.G., Reedy, R.C., Starr, R., Arnold, J.R., Drake, D.M., Englert, P.A., Metzger, A.E., Mitrofanov, I., Trombka, J.I., D'Uston, C., Wanke, H., Gasnault, O., Hamara, D.K., Janes, D.M., Marcialis, R.L., Maurice, S., Mikheeva, I., Taylor, G.J., Tokar, R., and Shinohara, C. (2002) Distribution of hydrogen in the near surface of Mars: evidence for subsurface ice deposits. Science 297:81-85.

Byrne, S., Dundas, C.M., Kennedy, M.R., Mellon, M.T., McEwen, A.S., Cull, S.C., Daubar, I.J., Shean, D.E., Seelos, K.D., Murchie, S.L., Cantor, B.A., Arvidson, R.E., Edgett, K.S., Reufer, A., Thomas, N., Harrison, T.N., Posiolova, L.V., and Seelos, F.P. (2009) Distribution of mid-latitude ground ice on Mars from new impact craters. Science 325:1674-1676.

Chevrier, V.F., Hanley, J., and Altheide, T.S. (2009) Stability of perchlorate hydrates and their liquid solutions at the Phoenix landing site, Mars. Geophys Res Lett 36, doi:10.1029/ 2009 GL037497.

Cull, S.C., Arvidson, R.E., Catalano, J.G., Ming, D.W., Morris, R.V., Mellon, M.T., and Lemmon, M. (2010a) Concentrated perchlorate at the Mars Phoenix landing site: evidence for thin film liquid water on Mars. Geophys Res Lett 37, doi:10.1029/ 2010 GL045269.
Cull, S.C., Arvidson, R.E., Morris, R.V., Wolff, M., Mellon, M.T., and Lemmon, M.T. (2010b) Seasonal ice cycle at the Mars Phoenix landing site: 2. Postlanding CRISM and ground observations. J Geophys Res: Planets 115, doi:10.1029/ 2009JE003410.

Cull, S.C., Kennedy, E., and Clark, A. (2014) Aqueous and nonaqueous soil processes on the northern plains of Mars: insight from the distribution of perchlorate salts at the Phoenix landing site and in Earth analog environments. Planet Space Sci 96:29-34.

Feldman, W.C., Boynton, W.V., Tokar, R.L., Prettyman, T.H., Gasnault, O., Squyres, S.W., Elphic, R.C., Lawrence, D.J., Lawson, S.L., Maurice, S., McKinney, G.W., Moore, K.R., and Reedy, R.C. (2002) Global distribution of neutrons from Mars: results from Mars Odyssey. Science 297:75-78.

Fischer, E., Martínez, G.M., Elliott, H.M., and Rennó, N.O. (2014) Experimental evidence for the formation of liquid saline water on Mars. Geophys Res Lett 41, doi:10.1002/2014GL060302.

Glavin, D.P., Freissinet, C., Miller, K.E., Eigenbrode, J.L., Brunner, A.E., Buch, A., Sutter, B., Archer, P.D., Jr., Atreya, S.K., Brinckerhoff, W.B., Cabane, M., Coll, P., Conrad, P.G., Coscia, D., Dworkin, J.P., Franz, H.B., Grotzinger, J.P., Leshin, L.A., Martin, M.G., McKay, C., Ming, D.W., NavarroGonzález, R., Pavlov, A., Steele, A., Summons, R.E., Szopa, C., Teinturier, S., and Mahaffy, P.R. (2013) Evidence for perchlorates and the origin of chlorinated hydrocarbons detected by SAM at the Rocknest aeolian deposit in Gale Crater. J Geophys Res 118:1955-1973.

Gough, R.V., Chevrier, V.F., Baustian, K.J., Wise, M.E., and Tolbert, M.A. (2011) Laboratory studies of perchlorate phase transitions: support for metastable aqueous perchlorate solutions on Mars. Earth Planet Sci Lett 312:371-377.

Hecht, M., Kounaves, S.P., Quinn, R.C., West, S.J., Young, S.M., Ming, D.W., Catling, D.C., Clark, B.C., Boynton, W.V., Hoffman, J., Deflores, L.P., Gospodinova, K., Kapit, J., and Smith, P.H. (2009) Detection of perchlorate and the soluble chemistry of martian soil at the Phoenix lander site. Science 325:64-67.

Heinz, J., Schulze-Makuch, D., and Kounaves, S.P. (2016) Deliquescence-induced wetting and RSL-like darkening of a Mars analogue soil containing various perchlorate and chloride salts. Geophys Res Lett 43:4880-4884.

Kok, J.F. and Rennó, N.O. (2009) A comprehensive numerical model of steady state saltation (COMSALT). J Geophys Res 114, doi:10.1029/2009JD011702.

Kounaves, S.P., Chaniotakis, N.A., Chevrier, V.F., Carrier, B.L., Folds, K.E., Hansen, V.M., McElhoney, K.M., O'Neil, G.D., and Weber, A.W. (2014) Identification of the perchlorate parent salts at the Phoenix Mars landing site and possible implications. Icarus 232:226-231.

Lewis, S.R., Collins, M., Read, P.L., Forget, F., Hourdin, F., Fournier, R., Hourdin, C., Talagrand, O., and Huot, J.-P. (1999) A climate database for Mars. J Geophys Res 104:24177-24194.

Marion, G.M., Catling, D.C., Zahnle, K.J., and Claire, M.W. (2010) Modeling aqueous perchlorate chemistries with applications to Mars. Icarus 207:675-685.

Martín-Torres, F.J., Zorzano, M.-P., Valentín-Serrano, P., Harri, A.M., Genzer, M., Kemppinen, O., Rivera-Valentin, E.G., Jun, I., Wray, J., Bo Madsen, M., Goetz, W., McEwen, A.S., Hardgrove, C., Rennó, N., Chevrier, V.F., Mischna, M., Navarro-González, R., Martínez-Frías, J., Conrad, P., McConnochie, T., Cockell, C., Berger, G., R. Vasavada, A., Sumner, D., and Vaniman, D. (2015) Transient liquid water and water activity at Gale Crater on Mars. Nat Geosci 8:357-361. 
Martínez, G.M., Rennó, N.O., and Elliott, H.M. (2012) The evolution of the albedo of dark spots observed on Mars polar region. Icarus 221:816-830.

Martínez, G.M., Fischer, E., Rennó, N.O., Sebastián, E., Kemppinen, O., Bridges, N., Borlina, C.S., Meslin, P.-Y., Genzer, M., Harri, A.-H., Vicente-Retortillo, A., Ramos, M., de la Torre Juárez, M., Gómez, F., and Gómez-Elvira, J. (2015) Likely frost events at Gale Crater: analysis from MSL/ REMS measurements. Icarus 280:93-102.

McEwen, A., Ojha, L., Dundas, C.M., Mattson, S.S., Byrne, S., Wray, J.J., Cull, S.C., Murchie, S.L., Thomas, N., and Gulick, V.C. (2011) Seasonal flows on warm martian slopes. Science 333:740-743

Meslin, P.-Y., Gasnault, O., Forni, O., Schröder, S., Cousin, A., Berger, G., Clegg, S.M., Lasue, J., Maurice, S., Sautter, V., Le Mouélic, S., Wiens, R.C., Fabre, C., Goetz, W., Bish, D., Mangold, N., Ehlmann, B., Lanza, N., Harri, A.M., Anderson, R., Rampe, E., McConnochie, T.H., Pinet, P., Blaney, D., Léveillé, R., Archer, D., Barraclough, B., Bender, S., Blake, D., Blank, J.G., Bridges, N., Clark, B.C., DeFlores, L., Delapp, D., Dromart, G., Dyar, M.D., Fisk, M., Gondet, B., Grotzinger, J., Herkenhoff, K., Johnson, J., Lacour, J.L., Langevin, Y., Leshin, L., Lewin, E., Madsen, M.B., Melikechi, N., Mezzacappa, A., Mischna, M.A., Moores, J.E., Newsom, H., Ollila, A., Perez, R., Rennó, N., Sirven, J.B., Tokar, R., de la Torre, M., d'Uston, L., Vaniman, D., Yingst, A.; MSL Science Team. (2013) Soil diversity and hydration as observed by ChemCam at Gale Crater, Mars. Science 341, doi:10.1126/science.1238670.

Ming, D.W., Archer, P.D., Jr., Glavin, D.P., Eigenbrode, J.L., Franz, H.B., Sutter, B., Brunner, A.E., Stern, J.C., Freissinet, C., McAdam, A.C., Mahaffy, P.R., Cabane, M., Coll, P., Campbell, J.L., Atreya, S.K., Niles, P.B., Bell, J.F., III, Bish, D.L., Brinckerhoff, W.B., Buch, A., Conrad, P.G., Des Marais, D.J., Ehlmann, B.L., Fairén, A.G., Farley, K., Flesch, G.J., Francois, P., Gellert, R., Grant, J.A., Grotzinger, J.P., Gupta, S., Herkenhoff, K.E., Hurowitz, J.A., Leshin, L.A., Lewis, K.W., McLennan, S.M., Miller, K.E., Moersch, J., Morris, R.V., Navarro-González, R., Pavlov, A.A., Perrett, G.M., Pradler, I., Squyres, S.W., Summons, R.E., Steele, A., Stolper, E.M., Sumner, D.Y., Szopa, C., Teinturier, S., Trainer, M.G., Treiman, A.H., Vaniman, D.T., Vasavada, A.R., Webster, C.R., Wray, J.J., Yingst, R.A.; MSL Science Team. (2014) Volatile and organic compositions of sedimentary rocks in Yellowknife Bay, Gale Crater, Mars. Science 343, doi:10.1126/science.1245267.

Mitrofanov, I., Anfimov, D., Kozyrev, A., Litvak, M., Sanin, A., Tret'yakov, V., Krylov, A., Shvetsov, V., Boynton, W., Shinohara, C., Hamara, D., and Saunders, R.S. (2002) Maps of subsurface hydrogen from the High Energy Neutron Detector, Mars Odyssey. Science 297:78-81.

Möhlmann, D.T.F. (2008) The influence of van der Waals forces on the state of water in the shallow subsurface of Mars. Icarus 195:131-139.

Möhlmann, D.T.F. (2011) Latitudinal distribution of temporary liquid cryobrines on Mars. Icarus 214:236-239.

Nuding, D.L., Rivera-Valentin, E.G., Davis, R.D., Gough, R.V., Chevrier, V.F., and Tolbert, M.A. (2014) Deliquescence and efflorescence of calcium perchlorate: an investigation of stable aqueous solutions relevant to Mars. Icarus 243:420-428.

Nuding, D.L., Davis, R.D., Gough, R.V., and Tolbert, M.A. (2015) The aqueous stability of a Mars salt analog: instant Mars. J Geophys Res: Planets 120:588-598.

Ojha, L., Wilhelm, M.B., Murchie, S.L., McEwen, A.S., Wray, J.J., Hanley, J., Massé, M., and Chojnacki, M. (2015) Spectral evidence for hydrated salts in recurring slope lineae on Mars. Nat Geosci 8:829-832.

Rennó, N.O., Bos, B.J., Catling, D., Clark, B.C., Drube, L., Fisher, D., Goetz, W., Hviid, S.F., Keller, H.U., Kok, J.F., Kounaves, S.P., Leer, K., Lemmon, M., Madsen, M.B., Markiewicz, W.J., Marshall, J., McKay, C., Mehta, M., Smith, M., Zorzano, M.P., Smith, P.H., Stoker, C., and Young, S.M.M. (2009) Possible physical and thermodynamical evidence for liquid water at the Phoenix landing site. $J$ Geophys Res 114, doi:10.1029/2009JE003362.

Savijärvi, H.I., Harri, A.M., and Kemppinen, O. (2015) Mars Science Laboratory diurnal moisture observations and column simulations. J Geophys Res: Planets 120:1011-1021.

Schorghofer, N. and Aharonson, O. (2005) Stability and exchange of subsurface ice on Mars. J Geophys Res: Planets 110, doi:10.1029/2004JE002350.

Smith, P.H., Tamppari, L.K., Arvidson, R.E., Bass, D., Blaney, D., Boynton, W.V., Carswell, A., Catling, D.C., Clark, B.C., Duck, T., Dejong, E., Fisher, D., Goetz, W., Gunnlaugsson, H.P., Hecht, M.H., Hipkin, V., Hoffman, J., Hviid, S.F., Keller, H.U., Kounaves, S.P., Lange, C.F., Lemmon, M.T., Madsen, M.B., Markiewicz, W.J., Marshall, J., McKay, C.P., Mellon, M.T., Ming, D.W., Morris, R.V., Pike, W.T., Rennó, N., Staufer, U., Stoker, C., Taylor, P., Whiteway, J.A., and Zent, A.P. (2009) $\mathrm{H}_{2} \mathrm{O}$ at the Phoenix landing site. Science 325:58-61.

Vincendon, M., Forget, F., and Mustard, J. (2010) Water ice at low to midlatitudes on Mars. J Geophys Res 115, doi:10.1029/ 2010JE003584.

Wall, S.D. (1981) Analysis of condensates formed at the Viking 2 lander site: the first winter. Icarus 47:173-183.

Whiteway, J.A., Komguem, L., Dickinson, C., Cook, C., Illnicki, M., Seabrook, J., Popovici, V., Duck, T.J., Davy, R., Taylor, P.A., Pathak, J., Fisher, D., Carswell, A.I., Daly, M., Hipkin, V., Zent, A.P., Hecht, M.H., Wood, S.E., Tamppari, L.K., Rennó, N., Moores, J.E., Lemmon, M.T., Daerden, F., and Smith, P.H. (2009) Mars water-ice clouds and precipitation. Science 325:68-70.

Zandonadi, D., Jr., Rennó, N.O., and Fischer, E. (2015) WETa soil wetness sensor for Mars. In $66^{\text {th }}$ International Astronautical Congress, Jerusalem, Israel.

Zhang, Y.-H. and Chan, C.K. (2003) Observations of water monomers in supersaturated $\mathrm{NaClO}_{4}, \mathrm{LiClO}_{4}$, and $\mathrm{Mg}\left(\mathrm{ClO}_{4}\right)_{2}$ droplets using Raman spectroscopy. J Phys Chem A 107:59565962.

Address correspondence to: Erik Fischer

Department of Climate and Space Sciences and Engineering Space Research Building University of Michigan 2455 Hayward St. Ann Arbor, MI 48109-2143

E-mail: erikfis@umich.edu

Submitted 3 May 2016 Accepted 30 August 2016

\section{Abbreviations Used}

FWHM $=$ full width half maximum

LTST = local true solar time

MMEC $=$ Michigan Mars Environmental Chamber 